\title{
Fitness, body weight loss and inappropriate shocks of subcutaneous-implantable cardioverter-defibrillator - a case report.
}

\author{
Diana Paskudzka ${ }^{1}$, Agnieszka Kolodzinska ${ }^{1}$, Łukasz Januszkiewicz ${ }^{2}$, and Marcin \\ Grabowski ${ }^{1}$ \\ ${ }^{1}$ Warszawski Uniwersytet Medyczny \\ ${ }^{2}$ Warszawski Uniwersytet Medyczny 1 Wydzial Lekarski
}

September 16, 2020

\begin{abstract}
The subcutaneous implantable cardioverter-defibrillator (S-ICD) is a well-established method for the prevention of sudden cardiac arrest and an alternative to the transvenous implantable cardioverter-defibrillator (TV-ICD). It is preferred mainly for young patients with long life expectancy, high risk of transvenous lead complications or history of previous endocarditis, or device infections. For both S-ICD and TV-ICD, inappropriate therapies are possible. For S-ICD, the most common cause of inappropriate shocks is T wave oversensing (TWOS), while in TV-ICD - supraventricular tachycardia. We present the case of a 38-year-old patient who reported a shock during physical exercise - crunches.
\end{abstract}

Title: Fitness, body weight loss and inappropriate shocks of subcutaneous-implantable cardioverterdefibrillator - a case report.

Short title: S-ICD: inappropriate shock.

Authors:

Diana Paskudzka ${ }^{1}$, MD, Agnieszka Kołodzińska ${ }^{1}$, MD, PhD, Łukasz Januszkiewicz ${ }^{1}$, MD, PhD, Marcin Grabowski ${ }^{1} \mathrm{MD}$, Professor,

1_-1st Department of Cardiology, Medical University of Warsaw, Warsaw, Poland

1st Department of Cardiology, Medical University of Warsaw

1a Banacha Street, 02-097 Warsaw, Poland,

phone: +48225992958

Address for correspondence:

Diana Paskudzka, 1st Department of Cardiology, Medical University of Warsaw, 1a Banacha Street, 02-097 Warsaw, Poland, phone: +48 2259929 58, +48514377067

Conflict of interest: None declared

Abstract

The subcutaneous implantable cardioverter-defibrillator (S-ICD) is a well-established method for the prevention of sudden cardiac arrest and an alternative to the transvenous implantable cardioverter-defibrillator 
(TV-ICD). It is preferred mainly for young patients with long life expectancy, high risk of transvenous lead complications or history of previous endocarditis, or device infections. For both S-ICD and TV-ICD, inappropriate therapies are possible. For S-ICD, the most common cause of inappropriate shocks is T wave oversensing (TWOS), while in TV-ICD - supraventricular tachycardia. We present the case of a 38-year-old patient who reported a shock during physical exercise - crunches.

Indroduction

The S-ICD is an established therapy for prevention of sudden cardiac death and an alternative to TV-ICD in selected patients. These types of devices are especially recommended for young patients with long life expectancy, lack of venous access for TV-ICD implantation or high risk associated with leads or history of previous endocarditis or device infections. The first S-ICDs were introduced in 2009. Since then, improvements have been made to reduce the device's size, increase battery life and upgrade detection algorithms to prevent inappropriate shocks (1). The rate of inadequate shocks ranges from 4 to $25 \%$, and it's similar to a TV-ICD - 20-30\%. However, the mechanism is different. For S-ICD, up to $80 \%$ is caused by TWOS, particularly in selected patient populations (i.e. congenital heart disease, Brugada and long QT syndrome). In intravenous devices, TWOS presents up to $20 \%$ of cases (2-5). In the case of high risk of TWOS, it is worth considering performing an exercise test after the implantation to properly program the sensory vector (6). Changing the sensitivity of the device and sensing vector often helps to solve the problem (7). In addition, about 5 to $10 \%$ of the inappropriate shocks can be caused by noise related to myopotential oversensing (4). For an TV-ICD, the most common cause of inappropriate discharges is supraventricular tachycardia (8).

\section{Case reports}

A 38-year-old man with implanted S-ICD, visited the ambulatory clinic of implantable devices due to a shock of the device a few days earlier. The patient had a history of: implantation of S-ICD in secondary prevention (2017), dilated cardiomyopathy, chronic heart failure in NYHA II class, paroxysmal atrial fibrillation, pulmonary vein isolation (2019), obesity. Since cardiac arrest the patient has changed his lifestyle dramatically, started regular physical activity and lost about $20 \mathrm{~kg}$. Being in good general condition, without signs of exacerbation of heart failure, a few days ago the patient had got a shock. The patient did not lose consciousness. There were no prodromal symptoms.

The current follow-up revealed an episode detected by the device as ventricular fibrillation and then a highenergy discharge. Shock zone was programmed from $220 \mathrm{bpm}$ and conditional shock zone $200 \mathrm{bmp}$. Battery status was $64 \%$. On the basis of the recording from the device it was difficult to clearly determine whether it was an artifact and an inappropriate shock (Figure 1). The patient admitted that he was doing physical exercise - sit ups when it was a shock. Therefore, a provocative test was performed in the laboratory. The patient was asked to lie down on the couch and perform exercises such as during the episode. The myopotential oversensing of the device during the exercise was confirmed (Figure 2). The patient was advised to avoid such and similar exercises.

References

1. Kaya E, Rassaf T, Wakili R. Subcutaneous ICD: Current standards and future perspective. Int J Cardiol Heart Vasc. 2019; 24: 100409.

2. Aydin A, Hartel F, Schlüter M, et al. Shock efficacy of subcutaneous implantable cardioverterdefibrillator for prevention of sudden cardiac death: initial multicenter experience. Circ Arrhythm Electrophysiol 2012; 5(5): 913-9.

3. Köbe J, Reinke F, Meyer C, et al. Implantation and follow-up of totally subcutaneous versus conventional implantable cardioverter defibrillators: a multicenter case-control study. Heart Rhythm 2013; 10(1): 29-36.

4. Olde Nordkamp LR, Dabiri Abkenari L, Boersma LV, et al. The entirely subcutaneous implantable cardioverter-defibrillator: initial clinical experience in a large Dutch cohort. J Am Coll Cardiol 2012; 60(19): 1933-9. 
5. Jarman JW, Todd DM. United Kingdom national experience of entirely subcutaneous implantable cardioverter-defibrillator technology: important lessons to learn. Europace 2013; 15(8): 1158-65.

6. Kooiman KM, Knops RE, Olde Nordkamp L, et al. Inappropriate subcutaneous implantable cardioverter defibrillator shocks due to $\mathrm{T}$-wave oversensing can be prevented: implications for management. Heart Rhythm 2014; 11(3): 426-34.

7. Corzani A, Ziacchi M, Biffi M, et al. Inappropriate shock for myopotential over-sensing in a patient with subcutaneous ICD. Indian Heart J. 2015;67(1):56-59.

8. De Maria E, Olaru A, Cappelli S. The entirely subcutaneous defibrillator (s-icd): state of the art and selection of the ideal candidate. Curr Cardiol Rev. 2015; 11(2): 180-186.
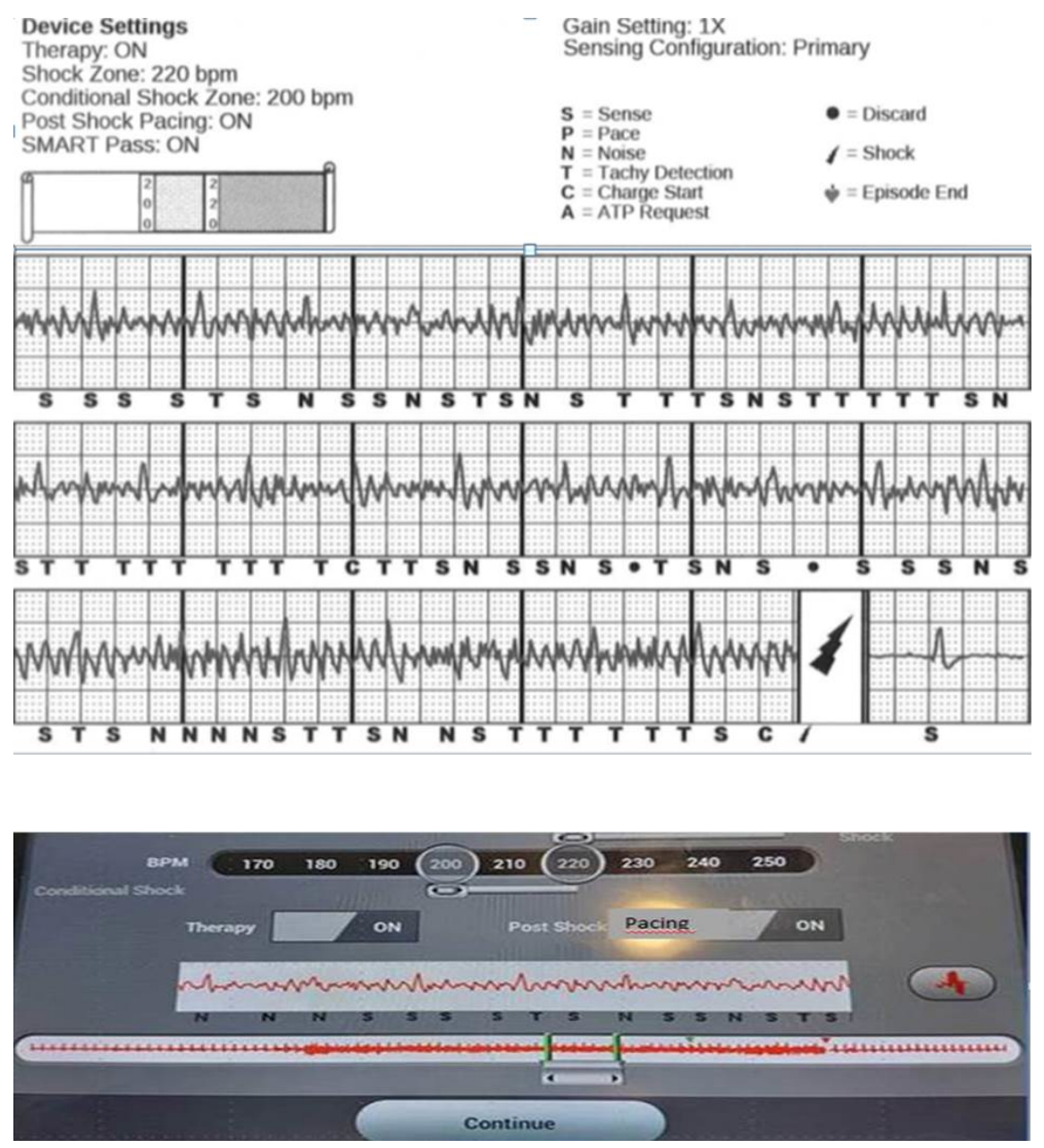